\title{
FERTILITY IN MARRIED WOMEN
}

\author{
MARY BARTON \\ 10 Wimpole Street, London, W.1 \\ (Received 9th March 1967, accepted 30th November 1967)
}

\begin{abstract}
Summary. The practice of AID designed to compensate for male sterility provides otherwise inaccessible data concerning the reproductive potential of nulligravidae in the general population. In the present analysis of 431 cases, preliminary investigation revealed a $76 \%$ incidence of unsuspected infecundity, the commonest factor being cervical dysfunction. Between 1955 and 1962 the conception rate increased from approximately $58 \%$ in a former series (1944-54) to $67 \%$. The conception rate was higher in those receiving preliminary treatment than in the stigma-free cases, reflecting the rapid augmentation of diagnostic and therapeutic measures.

The abortion rate over the whole period of 18 years remained constant, possibly revealing the irreducible incidence of embryological abnormality.
\end{abstract}

\section{INTRODUGTION}

The application by Moench in 1931 of microscopical methods to the study of semen led to the recognition of the role of male infertility in the infertile marriage; subsequently he observed that irreversible sterility occurred in men who did not present any obvious clinical abnormality accountable for childlessness. The comparatively high frequency of male sterility led to a search for a solution to the problem of the sterile marriage due to the male, when adoption was unacceptable. Thus it was for these cases of apparently normal women married to irreversibly sterile men, that AID was introduced.

During 27 years of systematic use, AID, although originally designed to compensate for male sterility, has yielded information concerning female infertility. Since variations in the male factor are virtually eliminated by the selection and use of highly fertile semen, given the correct planning of procedure, the conception rate and the number of inseminations required to procure fertilization should yield information concerning individual and group fertility in the general population of women of child-bearing age.

\section{MATERIAL AND METHODS}

The material presented here relates to 431 women of mean age 29 years (range 21 to 41 years) who underwent AID in the 8 years between lst January 1955 and 31st December 1962. Previously the histories of 600 cases treated in the 
10 years 1944-54 were analysed by the sampling technique described by Barton (1955). In the present series two samples were drawn at random by a disinterested person from the total 431 records and were also analysed. The size of the first sample was 100 cases and the subsequent sample 124 cases. The women in these samples requesting AID did so because their husbands had been proven sterile; they were thus not selected on the basis of their own fertility.

\section{OBSERVATIONS AND TREATMENT}

The records show a high incidence of relatively severe infertility factors observed at the preliminary examination, rendering it unlikely that conception would occur (Table 1). This high incidence $(76 \%)$ is seen in both samples.

TABLE 1

COMPARATIVE SUMMARIES OF INFERTILITY FACTORS REGORDED AT INITIAL EXAMINATION IN TWO SAMPLES OF 100 WOMEN APPLYING FOR A.I.D.

\begin{tabular}{l|c|c}
\hline & $\begin{array}{c}\text { Series 1 } \\
(1944-54)\end{array}$ & $\begin{array}{c}\text { Series } 2 \\
(1955-62)\end{array}$ \\
\hline Mean age (years) & $30 \cdot 3$ & 29 \\
\hline No stigmata & $25 \cdot 0 \%$ & $24.0 \%$ \\
Subfertile & $11 \cdot 0 \%$ & $23.0 \%$ \\
Hypoplasia & $4 \cdot 0 \%$ & $4.0 \%$ \\
Fibroids & $14 \cdot 0 \%$ & $7 \cdot 0 \%$ \\
Retroversion & $3 \cdot 0 \%$ & $1.0 \%$ \\
Endometrial disorders & $15 \cdot 0 \%$ & $13.0 \%$ \\
Tubal disorders & $10 \cdot 0 \%$ & $2 \cdot 0 \%$ \\
Ovarian disorders other than anovulation & $8 \cdot 0 \%$ & 0 \\
Anovulation or menstrual disorders & $19 \cdot 0 \%$ & $8 \cdot 0 \%$ \\
Pelvic infection & $44 \cdot 0 \%$ & $49.0 \%$ \\
Cervical dysfunction & $20 \cdot 0 \%$ & $11 \cdot 0 \%$ \\
Unspecified stigmata & & \\
\hline
\end{tabular}

Series 2 was all the more surprising since few women with manifest and severe reproductive disorders are referred by their physicians for AID on the basis of male deficiency. In every individual a search was made for conditions precluding or reducing fecundity. No patient was submitted to AID unless she was presumed suitable for, and capable of, conception. In many cases this entailed several months' preliminary treatment. Preliminary examinations were designed to establish whether the basic attributes of fecundity were present, e.g. whether cervical conditions permitted normal spermatozoal penetration and survival, whether the uterine cavity was adequate, the Fallopian tubes patent and functional, and to establish that ovulation was occurring regularly. Although the recognition of the conditions described in Table 1 and their correction was essential to success, discovery of these abnormalities often produced a mood of resentment or despair on the part of the patient. This attitude was quite unrelated to the prognosis because the wives of sterile or near sterile men often presume a compensatory high fertility in themselves and 
the contemplation of delay in the achievement of pregnancy presents itself as an obstacle invented by the clinician concerned.

In Table 1 only undoubted pathological or definite anatomical abnormalities have been included. Uterine hypoplasia was recognized where the combined length of the uterine cavity and cervical canal was under 2.5 in. 'Endometrial disorders' included hypertrophy of the endometrium, polypi and intra-uterine adhesions. 'Tubal disorders' related to occluded tubes and non-functional tubes with severe stenosis. Under 'ovarian disorders' only new growths were admitted. Pelvic infection was recorded only where inflammatory conditions of the endometrium or adnexa were present. Cervical dysfunction included cervicitis associated with negative invasion tests and positive bacteriological cultures but without clinical evidence of gross infection elsewhere in the genital tract.

Most of the women suffering from 'non-specific stigmata' were grossly obese, one had relapsing pyelitis with a double renal pelvis on the right side, one had severe anaemia, and one septic tonsils with extensive dental caries. In twenty-six cases more than one stigma was discovered.

TABLE 2

A GOMPARISON OF THE CONCEPTION RATE IN TWO SERIES OF 124 GASES

\begin{tabular}{l|c|c|c|c}
\hline & $\begin{array}{c}\text { Series } 1 \\
(1944-54)\end{array}$ & $\begin{array}{c}\text { Series } 2 \\
(1955-62)\end{array}$ & $\begin{array}{c}2-1 \\
\text { Difference }\end{array}$ & \multicolumn{1}{|c}{$\mathrm{P}^{*}$} \\
\hline $\begin{array}{l}\text { Overall } \\
\text { conception rate }\end{array}$ & $72 / 124=58 \cdot 1 \%$ & $83 / 124=66.9 \%$ & $+8.8 \%$ & $\begin{array}{l}>0 \cdot 1 \\
\text { Not significant } \\
\begin{array}{l}\text { Conception rate } \\
\text { in stigma free cases }\end{array}\end{array}$ \\
$\begin{array}{l}\text { Conception rate } \\
\text { in stigmatized cases }\end{array}$ & $32 / 65=67.3 \%$ & $17 / 30=56.7 \%$ & $-11.1 \%$ & $\begin{array}{l}\text { Not significant } \\
<0.01 \\
\text { Significant }\end{array}$ \\
\hline
\end{tabular}

${ }^{*} P=$ probability of chance occurrence (binomial distribution of proportions).

The overall conception rate is higher in Series 2 than in Series 1 but not significantly so.

The conception rate in stigma-free cases is less in Series 2 than in Series 1 but again not significantly.

In stigmatized cases that have been given treatment the conception rate is significantly higher in the second series $(P<0 \cdot 01)$.

In Series 1 the conception rate was higher in stigma-free cases than in stigmatized; in Series 2 it was higher in the stigmatized cases, but the chi-squared test showed that these differences were not significant.

A comparison of 100 cases in the series described in 1955 with 100 cases in the present series (Table 1) reveals a close similarity. Seventy-five per cent of the subjects in the first series and $76 \%$ of those in the second revealed, at the initial examination, conditions inconsistent with the occurrence of conception, the commonest being cervical dysfunction. A reduction in the frequency of ovulatory and endometrial (or menstrual) disorders in the second series probably reflected a greater selectivity by the practitioners referring the patients. It was observed that the proportion of patients acceptable at initial examination has not risen above one quarter of the total number applying for AID during the last series.

In Table 2 it will be seen that there was an improvement of not less than $9 \%$ in the overall conception rate in the second series. The mean number of cycles under treatment for positive cases was $5 \cdot 7$ compared with 4.3 in the first series. 
However, when the relative ages were considered, although women under 30 and those aged 30 to 35 years had a conception rate of $74 \%$, those in the age group 36 to 40 years showed a conception rate of $62 \%$. Thus, as in the first series, no dramatic fall in fertility occurred in the women over 35 years of age provided that they had responded satisfactorily to any necessary preliminary treatment. The improvement in the conception rate in the stigmatized cases in the second series is probably due to increased experience and the rapid augmentation of techniques, particularly the wider range of antibiotics in use, the improvements in radio-opaque media, the variety and potency of modern progestagens, methods of utero-tubal irrigation and the success of early surgical intervention in cases of endometriosis. Utero-tubal irrigation, now in routine use for the treatment of salpingitis or the sequelae of salpingitis either of pyogenic or tuberculous origin, has undoubtedly greatly improved the ultimate prognosis in such cases. It was often more effective than alternative routes in the application of antibiotics where endometritis and cervicitis of inflammatory type co-existed. Again, the local application of oestrogens by this method for utero-tubal hypoplasia often gave enhanced response.

It remains to explain the overall failure rate of $33 \%$ in the second series. Some of these failures undoubtedly reflect a constitutional susceptibility to infection. Passive treatment by antibiotics or active treatment by immunization, dilatation and cautery, or both, fail to protect some women from relapsing cervicitis, though it is not possible to explain why conception does not occur in the phases of remission. Exploratory laparotomy, culdoscopy or coelioscopy were not employed in this series; they might have revealed unexpected significant pelvic pathology.

The incidence of spontaneous abortion was $24.8 \%$; sixty-five out of 262 successive pregnancies terminated in abortion and all except one occurred in the first 10 weeks of pregnancy. Of these, $70 \%$ occurred in women in whom evidence of cervical infection was obtained at first examination, and the evidence suggests that these failures reflect primarily maternal factors. Only pregnancies confirmed by pregnancy test have been included but it may be assumed that some very early pregnancies, diagnosed only by the persistence of the luteal level of the waking temperature beyond 20 days (but with negative pregnancy tests) were missed pregnancies ending in missed abortions. Such cases where the conception may be associated with a defective trophoblast constitute the irreducible remnant which will escape detection by clinical methods and hence any estimate of the frequency of abortion must necessarily err on the low side. It has not been possible to demonstrate a correlation between the incidence of very early abortion and disruption or alteration of the normal time interval between insemination and ovulation. In the first series the abortion rate was $22.6 \%$ - a loss of sixty out of 265 successive pregnancies. Thus the considerable wastage of pregnancy has not been reduced by any of the therapeutic innovations introduced in the past few years.

Since inhibited cytokinesis is a characteristic of many human embryos which are thus doomed, perhaps it is not possible or even desirable that such blighted pregnancies should be saved, and that the abortion rate cannot be lowered below the frequency of embryological abnormality. 


\section{ACKNOWLEDGMENTS}

I would like to thank Dr Patricia P. Scott for assistance with the manuscript and Mrs M. E. Monk-Jones, M.Sc., for help with the statistics.

\section{REFERENCES}

Barton, M. (1955) Fertility in women. Stud. Fert. 7, 99.

Monnah, G. L. (1931) Z. Geburtsh. Gynäk. 99 (Beilageheft). 